\title{
Genetic diversity assessment in sorghum accessions using qualitative morphological and amplified fragment length polymorphism markers
}

\author{
Abe Shegro Gerrano ${ }^{1, \S}$, Maryke Tine Labuschagne ${ }^{1}$, Angeline van Biljon ${ }^{1}$, Nemera Geleta Shargie ${ }^{2}$
}

'University of the Free State - Dept. of Plant Sciences, P.O. Box 339 - Bloemfontein - 9300 - South Africa.

${ }^{2}$ Agricultural Research Council/Grain Crops Institute, Private Bag - X1251 - Potchefstroom 2520 - South Africa.

*Corresponding author <agerrano@arc.agric.za>

Edited by: Natalia de-Leon

Received August 01, 2013

Accepted March 30, 2014
ABSTRACT: Qualitative morphological and amplified fragment length polymorphism (AFLP) markers were compared for assessment of genetic diversity. Nine qualitative morphological traits were recorded to compare genetic relationships among 17 sorghum accessions with information derived from six AFLP primer combinations analysis. The mean morphological genetic similarity was lower in comparison to similarity computed using AFLP markers. Genetic similarity measured by AFLP markers was similar within the Ethiopian and South African material, as well as between South African and Ethiopian material. Morphological similarity was much higher in the Ethiopian material than in the South African material, indicating that the genotypes were related. The two techniques described genetic variability in different ways. Dendrogram generated from the morphological data matrix separated accession 216737 as being genetically distinct from the rest of the accessions. Accessions M101 and 97MW6127 were the most dissimilar accessions based on AFLP data.

Keywords: Dice similarity coefficient, genetic distance, marker, trait

\section{Introduction}

Information on genetic diversity has been successfully used for efficient germplasm management and utilisation (Frankel, 1989; Blakeney, 2002), genetic fingerprinting and genotype selection (IBPGR, 1993; Bucheyeki et al., 2009; FAO, 1998; Engles et al., 2002) in crop improvement. Morphological descriptors, biochemical and molecular markers are the methods used for measuring genetic diversity among crop species (Geleta and Labuschagne, 2005; Mehmood et al., 2008).

Morphological traits provide a simple way of measuring genetic diversity while studying genotype performance under normal growing conditions, but are influenced by environmental factors (Tuinstra et al., 1996; Beuningen and Busch, 1997; Abdi et al., 2002; Fufa et al., 2005).

Geleta and Labuschagne (2005) underlined the importance of using molecular markers as an additional tool for varietal description, as the genetic control of morphological traits is mostly polygenic and their expression depends on environmental factors. Molecular markers are invaluable for understanding the genetic make-up of agricultural crops. They differ from morphological traits in that they usually occur in greater numbers, they can be distinguished without relying on the complete development of the plant and their expression is not altered by the environment (Jeya Prakash et al., 2006; Tabbasam et al., 2006; Mehmood et al., 2008; Abu Assar et al., 2009).

Knowledge of genetic similarity/dissimilarity not only generates a better understanding of germplasm sampling, but also has implications with regard to choice of

\$Present address: Agricultural Research Council - Vegetable and Ornamental Plant Institute, Private Bag X293 - Pretoria 0001 - South Africa. parents for crosses and gene introgression from distantly related germplasm. Genetic diversity studies using a combination of techniques, such as morphological and molecular markers have been conducted in cotton (Gossypium hirsutum L.) (Bie et al., 2001; Wu et al., 2001), wheat (Triticum aestivum L.) (Cox and Murphy, 1990; Vieira et al., 2007) and oilseed crops (Riaz et al., 2003). Morphological, SSR and AFLP markers have also been compared to assess genetic diversity in maize (Zea mays L.) (Beyene et al., 2005) and have generated useful information about genetic diversity. Both morphological and molecular markers analyses are informative tools for estimating genetic distances (Vieira et al., 2007). Thus, this study aimed to compare the use of both morphological and AFLP markers to assess biodiversity in sorghum accessions.

\section{Materials and Methods}

Plant materials: the field experiment was conducted in North West Province, South Africa under rainfed conditions during the 2009 growing season. The farm is situated at $26^{\circ} 74^{\prime} \mathrm{S} ; 27^{\circ} 8^{\prime} \mathrm{E}, 1,344 \mathrm{~m}$ above sea level. The average minimum and maximum temperatures during the crop growing period are 16 and $29.48{ }^{\circ} \mathrm{C}$, respectively, with an annual total rainfall of $619 \mathrm{~mm}$. Seventeen sorghum accessions, seven from Ethiopia and 10 from South Africa were used for the comparison of morphological and AFLP markers. The accessions were sown in a plot size of $5 \mathrm{~m}$ $\times 0.9 \mathrm{~m}$ with three replications in a randomised complete block design. Each entry was planted in two rows, maintaining plant to plant a distance of $0.25 \mathrm{~m}$ and 1.5 $\mathrm{m}$ between blocks. Commercial fertilizer 3:2:1 (32) was applied at a rate of $100 \mathrm{~kg} \mathrm{ha}^{-1}$ at planting using fertilizer spreader, and LAN (28) was top-dressed manually when plants reached the knee height stage at the rate of 100 $\mathrm{kg} \mathrm{ha}^{-1}$. A pre-emergent herbicide was sprayed to control 
most annual broadleaved and some annual grass weeds. Additionally, hand weeding was used as needed, and a pesticide was applied to control stem borers.

Morphological markers: for qualitative characters (Table 1), the most frequent character state was recorded. Seed color, glume color, and leaf mid rib color were examined and scored using the Munsell color film (1990). For the other characters, data was recorded based on Sorghum descriptors (IBPGR, 1993) was used to categorise each accession morphologically. The morphological traits were coded as present (1) or absent (0) to compare them with AFLP marker data.

Morphological data analysis: the morphological data was analyzed using NTSYS-pc version 2.21c (Exeter Software, NY, USA). Similarity matrices were compiled for all pairs of accessions using Dice similarity coefficients (Dice, 1945), using SIMQUAL (similarity of qualitative data). Cluster analysis was done using the Unweighted PairGroup Method with Arithmetic Mean (UPGMA) analysis (Sokal and Michener, 1958) and dendrograms were constructed using the SAHN program. Similar analysis was done on AFLP and morphological data for comparison.

\section{Molecular marker}

DNA isolation: leaf material was harvested from three, three week-old plants from each sorghum accession. Young harvested leaves were freeze-dried and then ground to a fine powder using a Qiagen TissueLyser. The total genomic DNA was isolated from the tissuelysed material using the CTAB (hexadecyltrimethylammonium bromide) method (Saghai-Maroof et al., 1984). A volume of $750 \mu \mathrm{L}$ CTAB buffer [100 mM tris hydroxymethyl aminomethane, $\mathrm{pH} 8.0$ ); $20 \mathrm{mM}$ EDTA (ethylene-diaminetetra acetate), $\mathrm{pH} 8.0 ; 1.4 \mathrm{M} \mathrm{NaCl} ; 2 \%$ (w/v) CTAB; $0.2 \%$ (v/v) $\beta$-Mercaptho-ethanol] was added to approximately $250 \mu \mathrm{L}$ fine leaf powder in a $1.5 \mathrm{~mL}$ microfuge tube and incubated in a water bath at $65{ }^{\circ} \mathrm{C}$ for $1 \mathrm{~h}$. The suspension was extracted with $500 \mu \mathrm{L}$ chloroform: isoamylalcohol $[24: 1(\mathrm{v} / \mathrm{v})]$ and the phases separated by centrifugation at $12,000 \mathrm{~g}$ for $3 \mathrm{~min}$. DNA was precipitated from the aqueous phase with 0.66 volumes isopropanol at room temperature for $20 \mathrm{~min}$ and centrifuged at $12,000 \mathrm{~g}$ for
$10 \mathrm{~min}$. The precipitate was washed at room temperature with $500 \mu \mathrm{L} 70 \%(\mathrm{v} / \mathrm{v})$ ethanol for $20 \mathrm{~min}$ followed by centrifugation at $12000 \mathrm{~g}$ for $5 \mathrm{~min}$. The pellet was air-dried for $1 \mathrm{~h}$ and resuspended in TE buffer $(10 \mathrm{mM}$ tris hydroxymethyl aminomethane, $\mathrm{pH} 8.0 ; 1 \mathrm{mM}$ EDTA, $\mathrm{pH}$ 8.0). Resuspended DNA was precipitated with 0.75 $\mathrm{M}$ ammonium acetate and equal volume chloroform: isoamylalcohol $[24: 1(\mathrm{v} / \mathrm{v})]$. DNA was precipitated from the aqueous layer with two volumes of ice-cold absolute ethanol. After overnight incubation at $-20^{\circ} \mathrm{C}$, DNA was recovered by centrifugation at $12000 \mathrm{~g}$ for $15 \mathrm{~min}$ and washed twice with ice-cold $70 \%(\mathrm{v} / \mathrm{v})$ ethanol for $5 \mathrm{~min}$. The pellet was air-dried and resuspended in TE buffer and treated with $0.1 \mu \mathrm{g} \mu \mathrm{L}^{-1}$ DNase-free RNase for $2 \mathrm{~h}$ at $37^{\circ} \mathrm{C}$. DNA quantity and quality were estimated using a UV spectrophotometer by measuring absorbance at $A_{260}$ and $A_{280}$. DNA samples were diluted to a working solution of $200 \mathrm{ng} \mu \mathrm{L}^{-1}$.

AFLP data analysis: AFLP analysis was performed using six primer pair combinations (Table 2). MseI-primers were screened in combination with EcoRI-primers (EcoRI and $M s e \mathrm{I}$ primers were given names beginning with $\mathrm{E}$ and $M$, respectively. The code following $E$ or $M$ refers to the three selective nucleotides at the 3 '-end of the primer. This coding system was used throughout). Primers and adapters were synthesized by Integrated DNA Technologies Inc. (Coralville, USA). Oligonucleotides used for adapters were PAGE (polyacrylamide gel electrophoresis) purified. Adapters were prepared by adding equimolar amounts of both strands, heating for $10 \mathrm{~min}$ to $65^{\circ} \mathrm{C}$ in a water bath and then leaving the mixture to cool down to room temperature. AFLP analysis were performed as described by Vos et al. (1995) and modified by Herselman (2003).

Restriction digestion and ligation: genomic DNA $\mid \pm$ $1.0 \mu \mathrm{g}$ ) was digested using $4 \mathrm{U}$ of $\mathrm{MseI}$ (New England Prolabs) and $1 \mathrm{x}$ MseI-buffer [50 $\mathrm{mM} \mathrm{NaCl} ; 10 \mathrm{mM}$ tris hydroxymethyl aminomethane, $\mathrm{pH} 7.9 ; 10 \mathrm{mM} \mathrm{MgCl}_{2} ; 0.1$ mM DTT (dithiotreitol)] in a final volume of $50 \mu \mathrm{L}$ for 5 $\mathrm{h}$ at $37{ }^{\circ} \mathrm{C}$. Following MseI digestion, DNA was further digested overnight at $37{ }^{\circ} \mathrm{C}$ with $5 \mathrm{U}$ EcoRI and $\mathrm{NaCl}$ to a final concentration of $100 \mathrm{mM}$. Adapter ligation of the digested DNA was obtained by adding a solution contain-

Table 1 - List of qualitative characters recorded in the study.

\begin{tabular}{lcl}
\hline Qualitative characters & Code & Description \\
\hline Leaf mid rib color & LMC & White (1), Dull green (2), Yellow (3) \\
Plant color & PC & Pigmented (1) and Tan (2) \\
Panicle compactness and shape & PCS & Semi-loose erect primary branches (6), Semi-loose dropping primary branches (7), semi-compact elliptic (8) \\
Glume color & GLC & White (1), Brown (3), Red (4), Black (6) \\
Grain covering & GCOV & $25 \%$ grain covered (1), 50\% grain covered (3), 75 \% grain covered (5) \\
Grain color & GCOL & White (1), Yellow (2), Red (3), Brown (4) \\
Grain size & GSI & Small (1), Bold (2), Medium (3) \\
Grain shape & GSH & Round (1), Eliptical (2), Flat(3) \\
Grain luster & GLU & Lusterous (1), Non-lusterous (2) \\
\hline
\end{tabular}


Table 2 - EcoRI and Msel adapter, primer+1 and primer+3 sequences used in AFLP analysis.

\begin{tabular}{lll}
\hline Enzyme & \multicolumn{1}{c}{ Type } & \multicolumn{1}{c}{ Sequence (5'-3') } \\
\hline EcoRl & Adapter-F & CTCGTAGACTGCGTACC \\
& Adapter-R & AATTGGACGCAGTCTAC \\
Msel & Adapter-F & GACGATGAGTCCTGAG \\
& Adapter-R & TACTCAGGACTCAT \\
EcoRl & Primer+1 & GACTGCGTACCAATTCA \\
& Primer+3 & GACTGCGTACCAATTCACA \\
Msel & Primer+1 & GATGAGTCCTGAGTAAC \\
& Primer+3 & GATGAGTCCTGAGTACNN \\
& & CNN = CAC, CAG, CTA, CTC, CTG, CTT \\
\hline
\end{tabular}

ing 50 pmol MseI-adapter, 5 pmol EcoRI-adapter, 1 U T4 DNA Ligase (USB Corporation), $0.4 \mathrm{mM}$ ATP (adenosinetriphosphate) and 1x T4 DNA ligase buffer (66 mM tris hydroxymethyl aminomethane, $\mathrm{pH} 7.6 ; 6.6 \mathrm{mM} \mathrm{MgCl}_{2}$; $10 \mathrm{mM}$ DTT; $66 \mathrm{mM}$ ATP) followed by overnight incubation at $16{ }^{\circ} \mathrm{C}$.

Pre-amplification reactions: were carried out in $50 \mu \mathrm{L}$ reaction mixtures containing $5 \mu \mathrm{L}$ template DNA /restriction/ligation mixture), $30 \mathrm{ng}$ of each pre-amplification primer (EcoRI- and MseI-primer +1) (Table 2), 1x Promega Taq polymerase buffer $(10 \mathrm{mM}$ tris hydroxymethyl aminomethane, $\mathrm{pH} 9.0 ; 50 \mathrm{mM} \mathrm{KCl} ; 0.1 \%$ (v/v) Trition $\mathrm{x}$-100), $2 \mathrm{mM} \mathrm{MgCl}, 200 \mu \mathrm{M}$ of each dNTP and $1 \mathrm{U}$ Taq DNA polymerase (Promega, Madison, WI, USA). Amplifications were performed using the following cycling program: $5 \mathrm{~min}$ at $94{ }^{\circ} \mathrm{C}, 30$ cycles of $30 \mathrm{~s}$ at $94{ }^{\circ} \mathrm{C}, 60 \mathrm{~s}$ at 56 ${ }^{\circ} \mathrm{C}$ and $60 \mathrm{~s}$ at $72{ }^{\circ} \mathrm{C}$ and a final elongation of $10 \mathrm{~min}$ at $72{ }^{\circ} \mathrm{C}$. Quality and quantity of pre-amplification reactions were determined by electrophoresis in $1.5 \%(\mathrm{w} / \mathrm{v})$ agarose gels and diluted accordingly (1:5 to $1: 15$ times) prior to selective amplification.

Selective amplification: this was performed in a total volume of $20 \mu \mathrm{L}$ reaction containing $5 \mu \mathrm{L}$ of diluted preamplification product, 1x Promega Taq polymerase buffer, $2 \mathrm{mM} \mathrm{MgCl}_{2}, 200 \mu \mathrm{M}$ of each dNTP, $100 \mu \mathrm{g} \mathrm{mL}-1$ bovine serum albumin, $30 \mathrm{ng}$ MseI-primer + 3, $30 \mathrm{ng}$ EcoRI-primer +3 and 0.75 U Promega Taq DNA polymerase. The selective amplification cycling program consisted of: one cycle of denaturation at $94{ }^{\circ} \mathrm{C}$ for 5 min followed by one cycle of $30 \mathrm{~s}$ at $94{ }^{\circ} \mathrm{C}, 30 \mathrm{~s}$ at $65^{\circ} \mathrm{C}$ and $60 \mathrm{~s}$ at $72{ }^{\circ} \mathrm{C}$. The annealing temperature was reduced by $1^{\circ} \mathrm{C}$ per cycle during the next eight cycles after which 25 cycles were performed at $94^{\circ} \mathrm{C}$ for $30 \mathrm{~s}, 56^{\circ} \mathrm{C}$ for $30 \mathrm{~s}$ and $72^{\circ} \mathrm{C}$ for 60 s followed by one last elongation of $5 \mathrm{~min}$ at $72^{\circ} \mathrm{C}$. AFLP products were separated in denaturing polyacrylamide gels and DNA fragments visualised using silver staining.

Gel electrophoresis: polymerase chain reaction (PCR) products were mixed with $20 \mu \mathrm{L}$ formamide dye [98 \% (v/v) de-ionized formamide; $10 \mathrm{mM}$ EDTA, $\mathrm{pH} 8.0 ; 0.05$ $\%(\mathrm{w} / \mathrm{v})$ bromophenol blue; $0.05 \%$ (w/v) xylene cyanol] and denatured by incubation for $5 \mathrm{~min}$ at $95^{\circ} \mathrm{C}$. Mixtures were immediately placed on ice prior to loading. The PCR products $(2.5 \mu \mathrm{L})$ were separated on $5 \%(\mathrm{w} / \mathrm{v})$ denaturing polyacrylamide gels [19:1 acrylamide:bis-acrylamide; $7 \mathrm{M}$ urea; 1x TBE buffer (89 mM Tris-borate; $2.0 \mathrm{mM}$ EDTA)]. Electrophoresis was performed at a constant power of 80 $\mathrm{W}$ for approximately $2 \mathrm{~h}$.

Silver staining for DNA visualisation: The silver staining process for DNA visualisation of the denaturing acrylamide gels was done using the DNA Sequencing System of Promega. Gels were fixed in $10 \%(\mathrm{v} / \mathrm{v})$ acetic acid for $30 \mathrm{~min}$ and rinsed three times in de-ionized water, first for $10 \mathrm{~min}$ and $5 \mathrm{~min}$ each the last two washes. Gels were stained in a solution of $0.1 \%(\mathrm{w} / \mathrm{v})$ silver nitrate and 0.056 $\%(\mathrm{v} / \mathrm{v})$ formaldehyde for $30 \mathrm{~min}$ and rinsed in de-ionized water for $5 \mathrm{~s}$ before being immersed in a cold $\left(4\right.$ to $10{ }^{\circ} \mathrm{C}$ ) developing solution $[3 \%(\mathrm{w} / \mathrm{v})$ sodium carbonate; 0.056 $\%(\mathrm{v} / \mathrm{v})$ formaldehyde and $0.002 \mathrm{mg} \mathrm{mL}^{-1}$ thiosulphate] solution. Gels were shaken manually in the developer until DNA fragments became visible. $10 \%$ acetic acid was used to stop the developing process and shaking continued for a further 2 to $3 \mathrm{~min}$. The gel was rinsed in de-ionised water and left upright to dry overnight at room temperature. A photograph of the gel was taken by exposing the photographic paper (Ilford multigrade IV RC de Luxe) directly under the gel to dim light for $20 \mathrm{~s}$. This produced a negative image of the same size as the gel.

AFLP Data analysis: a binary matrix of specific AFLP fragments as present (1) or absent (0) was generated for each accession. Only reliable (between 300 and 700 bp) and repeatable bands (at least three repetitions) were considered. Pairwise, genetic distances were expressed as the complement of the Dice coefficient (Dice, 1945). Cluster analyses were performed using UPGMA (unweighted pair-group method using arithmetic averages; Sokal and Michener, 1958) analysis. Statistical analyses were performed using NTSYS-pc version 2.21c (Exeter Software, NY, USA). Dendrograms were created using the SAHN (Sequencial Agglomerative Hierarchical Nested) program of NTSYS and goodness of fit of clustering to data matrixes was calculated using COPH and MXCOMP programs and correlated with the original distance matrices in order to test for the association between the cluster in the dendrogram and the Dice matrix. AFLP data were evaluated using the Shannon Weaver diversity index $\left(\mathrm{H}^{\prime}\right)$ and polymorphic information content (PIC). The Shannon Weaver diversity index was calculated over all loci as described by Perry and Mclntosh (1991). The PIC for each primer combination was calculated, in order to identify its ability to generate variations, assess the quality of markers and to compare the effectiveness of each enzyme primer combination in rendering genetic information (Lanteri et al., 2004). PIC was calculated according to Riek et al. (2001) for the dominant marker as follows: PIC $=1-\left[\mathrm{f}^{2}+(1-\right.$ $f)^{2}$ ] where $f$ is the frequency of the marker in the data set. PIC values were averaged to provide PIC value for a primer-pair. A total of 186 AFLP fragments were scored as 
present (1) or absent $(0)$ and used for comparative analysis with morphological data.

\section{Results and Discussion}

\section{Genetic similarity based on morphological and AFLP data}

The genetic similarity for morphological descriptors ranged from 0.00 to 0.89 (Table 3 ) below diagonal), indicating that some accessions were morphologically very similar (0.89) while others were totally different (0.00). The average genetic distance for all pairwise comparisons $(\mathrm{N}=136)$ was 0.49 . A 0.89 similarity coefficient was obtained between accessions 97MW6113 and 216743, 97MW6129, NO253 and PI308453, as well as between PI308453 and 97MW6129 and Masekaswere and 216743.

Morphologically, these accessions were clustered together based on similarities in longest days to $50 \%$ flowering, highest number of leaves, shortest leaves, narrowest leaf width, smallest leaf area, the highest number of internodes, medium leaf sheath length, tallest plant, longest panicle, narrowest panicle, average panicle weight, lowest threshing percent, and highest number of primary branches per panicle. Furthermore, a high level of genetic similarity of 0.78 was observed for some accessions. The genetic similarity between M141 and 216737 was zero. These two accessions shared no similar morphological traits and were not related at all. These accessions were from South Africa and Ethiopia, respectively. The genetic similarity within the Ethiopian material (0.678) was much higher than within the South African material 10.43, data not shown). The genetic similarity between the South African and Ethiopian material was similar to that within the South African material (0.46).

The genetic similarity estimates for all pairwise combinations of the 17 accessions using AFLP data is pre- sented in Table 3 (above diagonal). The genetic similarity coefficients for AFLP data ranged from 0.88 to 0.98 . The average genetic similarity for all pairwise comparisons was 0.93 . The highest genetic similarity coefficient (0.98) was observed between accessions 97MW6129 and 97MW6127. This indicated that these two accessions were closely related and one cannot expect to make much genetic gain if they are chosen as parents for crossing. Both of these accessions were from Melkassa Agricultural Research Centre (MARC), Ethiopia.

The lowest genetic similarity $(0.88)$ was obtained between accessions M101 and 97MW6127. M101 was from South Africa while 97MW6127 was obtained from MARC and they were the most dissimilar accessions based on AFLP data in this study. Agrama and Tuinstra (2003) found genetic similarity values of 0.437 for SSR and 0.612 for RAPDs in 22 sorghum genotypes that were lower than the values obtained in this study. Selection of the parents, based on genetic distance information, could provide a basis for choosing parents for the crossing program (Zhong-hu, 1991).

Accessions PI308453 and 97MW6129 that had a similarity value of 0.89 based on morphological data were 0.97 similar based on AFLP data. The most similar accessions based on AFLP data were 97MW6129 and 97MW6127 (both from MARC), and accessions 216743 and 97MW6129, 97MW6127, NO253, PI308453 as well as 97MW6129 and 97MW6127, NO253; Macia-SA and M81, M101 and M81 and M105, as well as Masekaswere and Mamolokwane had a 0.78 similarity based on morphological data (second highest morphological value).

Accessions revealing the second highest similarity value (0.97) based on AFLP markers data were 97MW6113 and PI308453; Macia-SA and 216743; and M105 and M81. M141 and 216737 that shared no similarity based on morphological data $(0.00)$ had a genetic

Table 3 - Genetic distances for morphological (below diagonal) and amplified fragment length polymorphism (above diagonal) data based on Dice similarity coefficients for 17 sorghum accessions.

\begin{tabular}{|c|c|c|c|c|c|c|c|c|c|c|c|c|c|}
\hline No. & Accessions & 1 & 2 & 3 & 4 & 5 & 6 & 7 & 8 & 9 & 10 & 11 & 12 \\
\hline 1 & 216737 & 1.00 & 0.94 & 0.91 & 0.91 & 0.89 & 0.93 & 0.93 & 0.95 & 0.91 & 0.92 & 0.91 & 0.93 \\
\hline 2 & 216743 & 0.44 & 1.00 & 0.92 & 0.90 & 0.89 & 0.94 & 0.94 & 0.97 & 0.91 & 0.92 & 0.92 & 0.93 \\
\hline 3 & 97MW6129 & 0.44 & 0.78 & 1.00 & 0.98 & 0.96 & 0.97 & 0.94 & 0.93 & 0.93 & 0.95 & 0.93 & 0.93 \\
\hline 4 & 97MW6127 & 0.33 & 0.78 & 0.78 & 1.00 & 0.95 & 0.96 & 0.93 & 0.92 & 0.93 & 0.93 & 0.92 & 0.92 \\
\hline 5 & N0253 & 0.22 & 0.78 & 0.78 & 0.67 & 1.00 & 0.94 & 0.95 & 0.91 & 0.92 & 0.93 & 0.90 & 0.90 \\
\hline 6 & PI308453 & 0.33 & 0.78 & 0.89 & 0.78 & 0.78 & 1.00 & 0.97 & 0.95 & 0.95 & 0.94 & 0.93 & 0.93 \\
\hline 7 & 97MW6113 & 0.33 & 0.89 & 0.89 & 0.78 & 0.89 & 0.89 & 1.00 & 0.96 & 0.96 & 0.94 & 0.92 & 0.93 \\
\hline 8 & Macia-SA & 0.33 & 0.33 & 0.44 & 0.44 & 0.22 & 0.33 & 0.33 & 1.00 & 0.93 & 0.94 & 0.95 & 0.94 \\
\hline 9 & M48 & 0.44 & 0.44 & 0.44 & 0.33 & 0.44 & 0.44 & 0.56 & 0.11 & 1.00 & 0.92 & 0.92 & 0.91 \\
\hline 10 & M141 & 0.00 & 0.33 & 0.33 & 0.22 & 0.44 & 0.33 & 0.44 & 0.44 & 0.33 & 1.00 & 0.95 & 0.96 \\
\hline 11 & M81 & 0.33 & 0.22 & 0.44 & 0.22 & 0.22 & 0.33 & 0.33 & 0.78 & 0.22 & 0.67 & 1.00 & 0.97 \\
\hline 12 & M105 & 0.33 & 0.44 & 0.44 & 0.33 & 0.22 & 0.33 & 0.33 & 0.67 & 0.22 & 0.67 & 0.78 & 1.00 \\
\hline 13 & M101 & 0.44 & 0.33 & 0.44 & 0.44 & 0.22 & 0.33 & 0.33 & 0.78 & 0.22 & 0.22 & 0.56 & 0.44 \\
\hline 14 & M163 & 0.33 & 0.67 & 0.67 & 0.56 & 0.67 & 0.67 & 0.78 & 0.22 & 0.67 & 0.33 & 0.22 & 0.22 \\
\hline 15 & Masekaswere & 0.33 & 0.89 & 0.67 & 0.67 & 0.67 & 0.67 & 0.78 & 0.44 & 0.44 & 0.44 & 0.33 & 0.56 \\
\hline 16 & Mamolokwane & 0.44 & 0.67 & 0.56 & 0.67 & 0.44 & 0.56 & 0.56 & 0.33 & 0.44 & 0.33 & 0.33 & 0.56 \\
\hline 17 & M153 & 0.56 & 0.78 & 0.67 & 0.67 & 0.56 & 0.78 & 0.67 & 0.44 & 0.22 & 0.11 & 0.33 & 0.33 \\
\hline
\end{tabular}


similarity of 0.91 based on AFLP data. The most dissimilar accessions based on AFLP markers data, M101 and 97MW6127 (0.88) had a genetic similarity of 0.44 based on morphological data. The genetic similarity was much the same within the Ethiopian and South African material, as well as between the two groups of material 10.94 , 0.93 and 0.93 respectively, data not shown).

\section{Morphological cluster analysis}

The goodness of fit for the cluster analysis was confirmed by the cophenetic coefficient of $r=0.85$. This signified that the generated clusters accurately represented distances between accessions as determined by the similarity coefficients. The percentage similarity between accessions ranged from 33 to $89 \%$ (Figure 1). The resulting phenetic dendrogram revealed three main clusters (I, II and III, Figure 1) at a genetic distance of 0.33. Cluster I contained five accessions, subdivided into two sub-groups, M101 in one subgroup and M141, M105, M81 and MaciaSA in the second with a genetic similarity of 0.50 .

Accession M141 was separated from this group due to unique traits such as the semi-loose drooping primary branches, panicle type and black glume color and related to M105, M81 and Macia-SA. Accession M101 had pigmented plant color and flat grain shape which caused this accession to cluster separately from other accessions within the cluster. All accessions in cluster I were from South Africa and were characterised by $50 \%$ grain covering, small to medium grain size with white grain color and yellow leaf mid rib color. Furthermore, the cluster showed a tan type of plant, semi-loose, drooping primary branches, semi-compact elliptic panicle and non-lustrous as well as elliptical grain shape.

Accessions M141, M81 and M105 were introductions from ICRISAT to South Africa. The closest acces- sions in this cluster were M81 and Macia-SA with a genetic similarity coefficient of 0.78 . These accessions were clustered together based mainly on collection sites and pedigree relationship. Likewise, Bucheyekei et al. (2009), Dean et al. (1999) and Ghebru et al. (2002) detected clustering of sorghum accessions based on their collection site and pedigree relationship.

Cluster II contained the majority of accessions (Figure 1) and of those 11 accessions four were from Ethiopia, one from Purdue University (PU), one from ICRISAT and five from South Africa with varied morphological characters. Two accessions, M163 and M48 clustered separately at a genetic distance of 0.51 from the rest of the accessions and had a genetic similarity coefficient of 0.67 and were grouped based on red grain color. All accessions in this cluster were characterised by round grain shape, dull green leaf mid-rib color, with pigmented type of plant color, lustrous with elliptic shape of the grain, yellow grain color, and semi-compact elliptic type of panicle, bold seed size and $25 \%$ grain covering.

Two other accessions, Mamolokwane and Masekaswere clustered separately from the remaining seven accessions in cluster II, at a genetic similarity coefficient of 0.78. These accessions are landraces from South Africa and were collected in the Sekhukhune district of the Limpopo province. Among accessions grouped in cluster II, 216743 and 97MW6113 as well as 97MW6129 and PI308453 were the accessions that were most similar at a genetic similarity coefficient of 0.89 , indicating a higher morphological similarity.

Cluster III contained only accession 216737 that was linked with the other accessions at a genetic distance of 0.39 and was the most distant from the rest of the accessions. This accession is a landrace from Ethiopia and it was characterised by white leaf mid rib color, red glume



Figure 1 - Phenetic dendrogram generated using morphological data of 17 sorghum accessions depicting their relationships based on Unweighted Pair-Group Method with Arithmetic Mean clustering from pairwise comparisons employing the Dice genetic similarity coefficient. 
color, round grain shape, non lustrous grain and yellow grain color. The morphological dendrogram demonstrated variation of accessions based on morphological traits that could be a valuable source for sorghum improvement programs in the two geographical regions, Ethiopia and South Africa. Similarly, Geleta and Labuschagne (2005) found the existence of morphological variation among sorghum accessions collected from eastern parts of Ethiopia using 10 morphological traits and concluded that the variation among the sorghum germplasm implies the need for the genetic resource collection and maintenance.

Teshome et al. (1997) evaluated 117 sorghum accessions from the North Shewa and South Welo regions of Ethiopia based on 14 morphological traits and reported extensive variation of the accessions. Grenier et al. (2004) observed the morphological diversity among sorghum accessions as well as a high level of diversity within each region and was distributed with geographical origin using 2017 Sudanese sorghum landraces. Barro-Kondombo et al. (2010) also found a high level of morphological and genetic variability in sorghum varieties from Burkina Faso.

\section{Cluster analysis based on AFLP markers}

The dendrogram generated based on the Dice genetic similarity coefficient using UPGMA cluster analysis and AFLP marker data revealed four main clusters split into two main clusters at a genetic similarity coefficient of 0.927 (Figure 2). The four main clusters were split into two main clusters at a genetic similarity of 0.916 . The cophenetic correlation coefficient computed for the goodness of fit of the cluster analysis was 0.68 , which indicated a poor fit of the dissimilarity and cophenetic matrices.

Cluster I consisted of two accessions, Masekaswere and M101, at a genetic distance of 0.934 which were both from South Africa. Cluster II comprised five accessions, all from South Africa at a genetic similarity coefficient of 0.936. Accession Mamolokwane was clustered separately in this cluster and was the only landrace in the cluster. Cluster III contained seven accessions, three from Ethiopia, one from ICRISAT and one from PU and two from South Africa. M163 clustered separately from the rest of the accessions in this cluster with a 0.933 genetic dissimilarity coefficient and was from South Africa, indicating a unique accession. M48 was also from South Africa and genetically related to PI308453 and 97MW6113 with a 0.952 genetic dissimilarity coefficients, indicating that it might share some genetic information with accessions from Ethiopia and PU.

Cluster IV comprised three accessions, accession 216737 being dissimilar at a genetic distance of 0.944 in the group. Accessions 216737 and 216743 were collected from the same region, Gambella, Ethiopia and could have shared the same genetic background with Macia-SA which originated from South Africa. Agrama and Tuinstra (2003) reported the clustering of sorghum genotypes based on their geographical origins. Thus, selection of accessions as parental material based on their genetic distances and clustering could increase the genetic diversity among accessions. Sabharwal et al. (1995) and Chozin (2007) reported that sorghum parents with more diversity among themselves are expected to show a higher amount of variability. Abu Assar et al. (2009) found that the 40 genotypes studied in Sudan were clustered based on morphological and/or pedigree relationship using 16 SSRs primers.

\section{Comparison of morphological and AFLP dendro-} grams

Comparison of the morphological and AFLP dendrograms showed that some accessions clustered togeth-

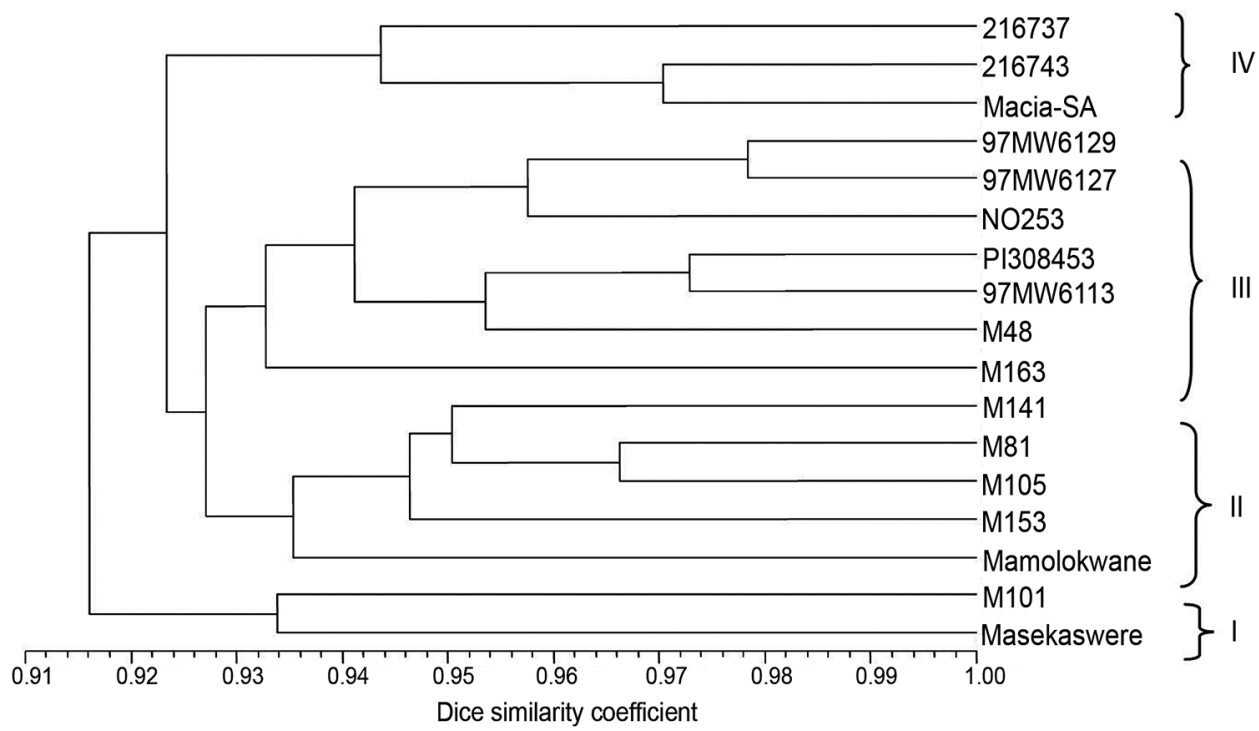

Figure 2 - Dendrogram generated based on the AFLP data using the Unweighted Pair-Group Method with Arithmetic Mean cluster analysis of Dice genetic similarity coefficients. 
er for both analyses (Figure 1 and 2). Accessions M163, M48，97MW6113，PI308453， NO253，97MW6127, 97MW6129 and 216743 clustered together in both morphological and AFLP dendrograms (clusters II, III and IV). Accessions that clustered differently in these clusters were M153, Masekaswere and Mamolokwane that clustered with the above mentioned accessions based on morphological data, but clustered separately from these accessions in another main group using AFLP data. Macia-SA also clustered differently based on morphological and AFLP data. M141, M105 and M81 clustered together using both morphological and AFLP data.

In the morphological dendrogram, accessions M48 and M163 were separated from cluster II at a genetic similarity of 0.51 , while in the AFLP dendrogram accession M163 was separated from the rest of the accessions in cluster III at a genetic similarity of 0.933 . This showed that accession M163 was both morphologically and genetically different from the rest of the accessions in the cluster. Accessions PI308453 and 97MW6129 as well as 97MW6113 and 216743 were the most similar based on the morphological data. However, AFLP data positioned them in different sub-clusters although they were still in the same main cluster (III).

Accession 216737 was the most distinct accession based on morphological clustering and grouped totally separately. However, it clustered together with accessions 216743 and Macia-SA in the AFLP dendrogram. Furthermore, landrace accessions Mamolokwane and Masekaswere grouped together in cluster II of the morphological dendrogram but in the AFLP dendrogram they were placed in different cluster groups. Accessions M81, M105 and M141 grouped together in both the morphological and AFLP dendrograms. AFLP molecular analysis is a good technique for discriminating and grouping closely related sorghum accessions and also to describe the origin and pedigree relationship among them. Similarly, Abu Assar et al. (2005) found that 96 sorghum genotypes were grouped together based on their geographic and pedigree relationships.

The genetic similarity ranged from 0.00 to 0.89 and 0.88 to 0.98 for morphological and AFLP markers, respectively. The genetic similarity for morphological data was generated by nine data points while AFLP analysis was based on 186 data points. Morphological data is based on the expression of a few genes that have been selected for, while AFLP analysis covers the entire genome and targets both expressed and unexpressed (but mainly unexpressed) genes that were not selected for. Genetic similarity was lower in the morphological data, but was very high in the AFLP data. Ritter et al. (2007) found a genetic dissimilarity value of 0.66 using AFLP data from 95 sorghum accessions that was lower than the values found in this study.

The morphological traits used were able to distinguish between accessions and the AFLP markers complemented the data obtained to separate closely related accessions.

\section{Acknowledgements}

The first author would like to acknowledge the World Bank through the Ministry of Agriculture and Rural Development, Benishangul-Gumuz Regional State of Ethiopia for its financial support and the Institute of Biodiversity Conservation/Ethiopia and Agricultural Research Council-Grain Crops Institute/South Africa for providing the sorghum germplasm for the study.

\section{References}

Abdi, A.; Bekele, E.; Asfaw, Z.; Teshome, A. 2002. Patterns of morphological variation of sorghum [Sorghum bicolor (L.) Moench] landraces in qualitative characters in North Showa and South Welo, Ethiopia. Hereditas 137: 161-172.

Abu Assar, A.H.; Uptmoor, R.; Abdelmula, A.A.; Wagner, C.; Salih, M.; Ali, A.A.; Ordon, F.; Friedt, W. 2009. Assessment of sorghum genetic resources for genetic diversity and drought tolerance using molecular markers and agro-morphological traits. University of Khartoum Journal of Agricultural Science 17: 1-22.

Abu Assar, A.H.; Uptmoor, R.; Abdelmula, A.A.; Salih, M.; Ordon, F.; Friedt, W. 2005. Genetic variation in sorghum germplasm from Sudan, ICRISAT, and USA assessed by simple sequence repeats (SSRs). Crop Science 45: 1636-1644.

Agrama, H.A.; Tuinstra, M.R. 2003. Phylogenetic diversity and relationships among sorghum accessions using SSRs and RAPDs. African Journal of Biotechnology 2: 334-340.

Barro-Kondombo, C.; Sagnard, F.; Chantereau, J.; Deu, M.; Brocke, K.V.; Durand, P.; Goze, E.; Zongo, J.D. 2010. Genetic structure among sorghum landraces as revealed by morphological variation and microsatellite markers in three agro climatic regions of Burkina Faso. Theoretical and Applied Genetics 120: 1511-1523.

Bie, S.; Kong, F.L.; Zho, Y.Y.; Zhang, G.M.; Wang, X.G. 2001. Genetic diversity and analysis of representative elite cotton varieties in three main cotton regions in China by RAPDs and its relation with agronomic characters. Scientia Agricultura Sinica 34: 597-603.

Beuningen, L.T. van; Busch, R.H. 1997. Genetic diversity among North American spring wheat cultivars: III. Cluster analysis based on quantitative morphological traits. Crop Science 37: 981-988.

Beyene, Y.; Botha, A.M.; Myburg, A.A. 2005. A comparative study of molecular and morphological methods of describing genetic relationships in traditional Ethiopian highland maize. African Journal of Biotechnology 4: 586-595.

Blakeney, M. 2002. Intellectual property, biological diversity and agricultural research in Australia. Australian Journal of Agricultural Research 53: 127-147.

Bucheyekei, T.L.; Gwanama, C.; Mgonja, M.; Chisi, M.; Folkertsma, R.; Mutegi, R. 2009. Genetic variability characterisation of Tanzania sorghum landraces based on Simple Sequence Repeats (SSRs) molecular and morphological markers. Journal African Crop Science 17: 71-86.

Chozin, M. 2007. Characterisation of sorghum accessions and choice of parents for hybridization. Journal of Akta Agrosia Edisi Khusus 2: 227-232. 
Cox, T.S.; Murphy, J.P. 1990. The effects of parental divergence of $\mathrm{F}_{2}$ heterosis in winter wheat regions of United States. Proceedings of the National Academy of Sciences of the United States of America 83: 5583-5586.

Dean, R.E.; Dahlberg, J.A.; Hopkins, M.S.; Mitchell, S.E.; Kresovich, S. 1999. Genetic redundancy and diversity Among sorghum accessions in the U.S.A. national sorghum collection as assessed with simple sequence repeats (SSRs) markers. Crop Science 39: 1215-1221.

Dice, L.R. 1945. Measures of amount of ecologic association between species. Ecology 26: 297-302.

Engles, J.M.M.; Rao, V.R.; Brown, A.H.D.; Jackson, M.T. 2002. Managing Plant Genetic Diversity. CABI, Wallingford, UK.

Food and Agricultural Organization [FAO]. 1998. The States of the World's Plant Genetic Resources for Food and Agriculture. FAO, Rome, Italy.

Frankel, O.H. 1989. Practical considerations relevant to effective evaluation. In: Brown, A.H.D.; Frankel, O.H.; Marshall, D.R.; Williams, J.T., eds. The use of plant genetic resources. Cambridge University Press, Cambridge, UK.

Fufa, H.; Baenziger, P.S.; Beecher, B.S.; Dweikat, I.; Graybosch, R.A.; Eskridge, K.M. 2005. Comparison of phenotypic and molecular marker-based classifications of hard red winter wheat cultivars. Euphytica 145: 133-146.

Ghebru, B.; Schmidt, R.J.; Bennetzen, J.L. 2002. Genetic diversity of Eritrea sorghum landraces assessed with Simple sequence repeats (SSRs) markers. Theoretical and Applied Genetics 105: 229-236.

Geleta, N.; Labuschagne, M.T. 2005. Qualitative traits variation in sorghum (Sorghum bicolor (L.) Moench) germplasm from eastern highlands of Ethiopia. Biodiversity and Conservation 14: 3055-3064.

Grenier, C.; Bramel, P.J.; Dahlberg, J.A.; El-Ahmadi, A.; Mahmoud, M.; Peterson, G.C.; Rosenow, D.T.; Ejeta, G. 2004. Sorghums of the Sudan: analysis of regional diversity and distribution. Genetic Resources and Crop Evolution 51: 489-500.

Herselman, L. 2003. Genetic variation among Sothern African cultivated peanuts (Arachishypogaea L.) genotypes as revealed by AFLP analysis. Euphytica 133: 319-327.

International Board for Plant Genetic Resources [IBPGR]. 1993. Descriptors for Sorghum [Sorghum bicolor (L.) Moench]. IBPGR/ICRISAT, Rome, Italy.

Jeya Prakash, S.P.; Biji, K.R.; Gomez, S.M.; Murthy, K.G.; Babu, R.C. 2006. Genetic diversity analysis of sorghum [Sorghum bicolor (L.) Moench] accessions using RAPD markers. Indian Journal of Crop Science 1: 109-112.

Lanteri, S.; Saba, E.; Cadinu, M.; Mallica, G.M.; Baghino, L.; Portis, E. 2004. Amplified fragment length polymorphism for genetic diversity assessment in globe artichoke. Theoretical and Applied Genetics 108: 1534-1544.

Mehmood, S.; Bashir, A.; Ahmad, A.; Akram, Z.; Jabeen, N.; Gulfraz, M. 2008. Molecular characterisation of Regional sorghum bicolor varieties from Pakistan. Pakistan Journal of Botany 40: 2015-2021.

Munsell Color Film. 1990. The Munsell Book of Color: Matte Collection. New Windsor, New York, NY, USA.
Perry, M.C.; Mclntosh, M.S. 1991. Geographical patterns of variation in the USDA soybean germplasm collection: I. Morphological traits. Crop Science 31: 1350-1355.

Riaz, A.; Li, G.; Quresh, Z.; Swati, M.S.; Quiros, C.F. 2003. Genetic diversity of oilseed Brassica napus inbred lines based on sequence-related amplified polymorphism and its relation to hybrid performance. Plant Breeding 120: 411-415.

Riek, J.D.; Calsyn, E.; Everaert, I.; Van Bockstaele, E.; De Loose, M. 2001. AFLP based alternatives for the assessment of Distinctness, Uniformity and Stability of sugar beet varieties. Theoretical and Applied Genetics 103: 1254-1265.

Ritter, K.B.; McIntyre, C.L.; Godwin, I.D.; Jordan, D.R.; Chapman, S.C. 2007. An assessment of the genetic relationship between sweet and grain sorghums, within sorghum bicolor ssp. Bicolor (L.) Moench, using AFLP markers. Euphytica 157: 161-176.

Sabharwal, P.S.; Lodhi, G.P.; Grewal, R.P.S.; Pahuja, S.K.; Nehra, S.S. 1995. A study on genetic divergence in forage sorghum. Crop Research (India) 10: 279-284.

Saghai-Maroof, M.A.; Soliman, K.M.; Jorgensen, R.A. 1984. Ribosomal DNA spacer-length polymorphism in barely: Mendelian inheritance, chromosomal location, and population dynamics. Proceedings of the National Academy of Sciences of the United States of America 81: 8014-8018.

Sokal, R.R.; Michener, C.D. 1958. A statistical methods for evaluating relationships. University of Kansas Science Bulletin 38: 1409-1448.

Tabbasam, N.; Rahman, M.U.; Zafar, Y. 2006. DNA-Based genotyping of sorghum hybrids. Pakistan Journal of Botany 38: 1599-1604.

Teshome, A.; Baum, B.R.; Fahrig, L.; Torrance, J.K.; Arnason, T.J.; Lambert, J.D. 1997. Sorghum [Sorghum bicolor (L.) Moench] landrace variation and classification in North Showa and South Welo, Ethiopia. Euphytica 97: 255-263.

Tuinstra, M.R.; Grote, E.M.; Goldsbrough, P.B.; Ejeta, G. 1996. Identification of quantitative trait loci associated with preflowering drought tolerance in sorghum. Crop Science 36: 1337-1344.

Vieira, E.A.; Carvalho, F.I.F.; Bertran, I.; Kopp, M.M.; Zimmer, P.D.; Benin, G.; Silva, J.A.; Hartwig, I.; Malone, G.; Oliveira, A.C. 2007. Association between genetic distance in wheat (Triticum aestivum L.) as estimated by AFLP and morphological markers. Genetic and Molecular Biology 30: 392-399.

Vos, P.; Hogers, R.; Bleeker, M.; Reijans, M.; Lee, T.; Homes, M.; Frijters, A.; Pot, J.; Peleman, J.; Kuiper, M.; Zabeau, M. 1995. AFLP: A new technique for DNA fingerprinting. Nucleic Acids Research 23: 4407-4414.

Wu, Y.T.; Zhang, T.Z.; Yin, J.M. 2001. Genetic diversity detected by DNA markers and phenotypes in upland Cotton. Acta Genetica Sinica 28: 1040-1050.

Zhong-hu, H. 1991. An investigation of the relationship between the $\mathrm{F} 1$ potential and measures of genetic distance among wheat lines. Euphytica 58: 165-170. 